\title{
PERTENTANGAN KELAS SOSIAL PADA TOKOH UTAMA DALAM DRAMA THE HEIRS BERDASARKAN PERSPEKTIF SASTRA MARXIS
}

\author{
Abdul Basid a,*, Zulhizawati ${ }^{\mathrm{b}}, *$, Muh. Zuhdy Hamzah c,* \\ ${ }^{\text {a }}$ Fakultas Humaniora - UIN Maulana Malik Ibrahim Malang \\ Jalan Gajayana No. 50, Malang, Indonesia \\ ${ }^{\mathrm{b}}$ Fakultas Humaniora - UIN Maulana Malik Ibrahim Malang \\ Jalan Gajayana No. 50, Malang, Indonesia \\ ${ }^{\mathrm{c}}$ Fakultas Ilmu Tarbiyah dan Keguruan - UIN Maulana Malik Ibrahim Malang \\ Jalan Gajayana No. 50, Malang, Indonesia \\ *abdulbasid@bsa.uin-malang.ac.id \\ *zhizawati@gmail.com \\ *elzuhdyhamzah15@pgmi.uin-malang.ac.id
}

\begin{abstract}
Abstrak: Penelitian ini bertujuan untuk mengungkapkan bentuk pertentangan kelas sosial pada tokoh utama dalam drama The Heirs berdasarkan perspektif sastra Marxis dan penyebab terjadinya pertentangan kelas sosial pada tokoh utama dalam drama The Heirs berdasarkan perspektif sastra Marxis. Jenis penelitian ini adalah penelitian kualitatif deskriptif karena penelitian ini memaparkan fenomena pertentangan kelas sosial pada tokoh utama dalam drama The Heirs. Sumber data utama dalam penelitian ini adalah drama The Heirs. Teknik pengumpulan data yang digunakan adalah teknik tonton, teknik baca, dan teknik catat, sedangkan teknik analisis data yang digunakan model Miles dan Huberman yang terdiri dari empat tahapan, yaitu pengumpulan data, reduksi data, pemaparan data, dan penarikan kesimpulan. Penelitian ini menghasilkan simpulan sebagai berikut: yang pertama, bentuk pertentangan kelas sosial pada tokoh utama dalam drama The Heirs adalah penindasan; dan yang kedua, penyebab terjadinya pertentangan kelas sosial pada tokoh utama dalam drama The Heirs adalah: (a) implementasi sistem hirarki di SMA Jeguk dan (b) adanya hubungan asmara antara kelas borjuis dengan kelas proletar.
\end{abstract}

Kata Kunci: Drama, kelas sosial, Marxis, pertentangan

Abstract: In social life, social status is considered a prestigious thing. Social status determines how a person is in a community. Someone could be respected, glorified, sneered, humbled, or bullied because of the social status he has. Social status is also likely to be one of the causes of the emergence of conflicts among the community members. The goal of this research is to reveal forms and causes of the social class conflict of the main character in drama The Heirs based on the perspective of Marxist literary. This research was descriptive qualitative study. The main data source in this research was the TV drama entitled The Heirs. The data collection techniques included watching, reading, and recording. In the data analysis, this study used Miles and Huberman steps, namely collecting, reducing, displaying data, and drawing conclusion. The results of this research were: 1) the form of social class disagreement on the main character in The Heirs is oppression; and 2) the causes of the social class opposition to the main character in The Heirs are: a) the relationship between the bourgeoisie and the proletarian class; and b) the implementation of hierarchical system in Jeguk High School.

Keywords: conflicts, drama, Marxist, social class 


\section{PENDAHULUAN}

Kelas sosial merupakan suatu strata atau lapisan masyarakat yang memiliki kedudukan sama dalam rangkaian kesatuan status sosial. Kelas sosial merupakan bagian integral dari suatu masyarakat. Di mana ada masyarakat, maka di situ ada pula kelas sosial. Kelas sosial dapat muncul karena adanya beberapa perbedaan anggota masyarakat, seperti jenis kelamin, pekerja atau buruh dan majikan, kekayaan, dan lain sebagainya. Munculnya beberapa kelas dalam masyarakat dan adanya hubungan di antara kelas-kelas tersebut disebut dengan sistem kelas atau class system. Artinya adalah bahwa setiap anggota masyarakat memiliki kedudukan dalam masyarakat, mengetahuinya dengan sadar, dan diakui oleh anggota masyarakat (Soekanto, 1987:260).

Max dan Weber mendefinisikan bahwa yang menentukan strata kelas anggota masyarakat adalah aspek ekonomi. Artinya adalah bahwa strata anggota masyarakat dibedakan berdasarkan pada kekayaan yang dimiliki. Apabila seseorang memiliki kekayaan yang melimpah dan serba berkecukupan, maka ia menempati kaum atas atau termasuk dalam kategori kelas tinggi (high class). Namun sebaliknya apabila seseorang memiliki kekayaan yang pas-pasan dan cenderung kekurangan, maka ia termasuk dalam kategori kelas menengah (middle class), atau kelas rendah (lower class) (Sunarto, 1993:115).

Status seseorang dalam masyarakat dapat diperoleh melalui tiga cara, yaitu kelahiran (ascribed status), perjuangan (aschieved status), dan pemberian atau penghormatan (assigned status). Dalam kehidupan sosial, munculnya kelas sosial adalah sebuah keniscayaan. Artinya adalah bahwa selama manusia itu hidup bermasyarakat, maka pembagian kelas sosial akan selalu ada. Kelas sosial akan muncul secara alamiah, sehingga dalam kenyataannya munculnya kelas sosial telah menjadi bagian dari hukum alam (Setiadi, dan Usman, 2011:424-425).
Hukum pembagian status sosial itu ada seiring dengan tingkat keinginan manusia yang selalu menginginkan kehidupan yang layak dan lebih baik. Upaya-upaya itulah yang mengantarkan pembentukan pola-pola pembagian status sosial yang akan berkaitan dan beriringan dengan kemampuan dan kualifikasi intelektual serta fisik manusia yang berbeda-beda. Jika diperhatikan bentuk pemilahan manusia menurut bentuk fisik, maka akan muncul manusia dengan tingkat klasifikasi cantik, tampan, biasa saja, atau jelek. Berdasarkan hal ini maka dapat kita ketahui bahwa tingkat kualitas manusia akan sangat berhubungan dengan kapasitas mental intelektual, kemampuan, dan bentuk rupa fisiknya (Setiadi dan Usman, 2011:425).

Teori sastra Marxis lahir dilatarbelakangi oleh pandangan aliran Marxisme. Marxisme ini muncul didasari atas pemikiran Engels tentang ekonomi, sejarah, masyarakat, dan revolusi. Para akademisi yang meneliti sastra menggunakan pandangan Marxisme yang bersumber dari pemikiran Engels ini menggunakannya sebagai sebuah pendekatan dan teori sastra yang kemudian terkenal disebut dengan teori sastra Marxis. Fokus utama teori sastra Marxis adalah adanya gagasan bahwa sastra merupakan produk dari kekuatan sosial dan ideologi. Dalam konteks ini, Eagleton menyatakan bahwa teks sastra bukanlah sebuah ekspresi ideologi dan bukan pula ekspresi kelas sosial. Implikasi dari pendapat Eagleton tentang teks ini adalah bahwa teori sastra Marxis memiliki premis sederhana yang sama dan bahwa sastra hanya dapat dipahami dalam kerangka yang lebih besar dari realitas sosial (Jefferson dan Robey, 1989:167).

Berdasarkan peranan dan tingkat pentingnya, tokoh terdiri atas tokoh utama dan tokoh tambahan. Tokoh utama adalah tokoh yang menjadi pusat penceritaan. Karena menjadi pusat cerita, maka tokoh utama diceritakan dengan detail baik tatkala ia sebagai subyek dari sebuah peristiwa ataupun menjadi objek. Tokoh utama tidak selalu berupa perseorangan namun adakalanya tokoh utama digambarkan dalam 
bentuk komunitas masyarakat atau kelompok tertentu dalam masyarakat. Penentuan tokoh utama tergantung pada penulis atau sutradara. Ada beberapa cara yang digunakan dalam menentukan tokoh utama, yaitu tokoh yang paling berkaitan dengan tema cerita, tokoh yang paling banyak memiliki relasi atau kaitan dengan tokoh lain, atau tokoh yang memerlukan waktu atau setting penceritaan lebih banyak daripada tokohtokoh yang lain. Sedangkan tokoh tambahan adalah tokoh yang menjadi pelengkap dari tokoh utama. Tokoh tambahan ini digambarkan dalam latar yang hanya berkaitan dengan cerita tokoh utama secara langsung (Nurgiyanto, 2007:176).

Dalam penelitian ini, peneliti akan meneliti sebuah drama "The Heirs". Drama ini merupakan salah satu drama Korea yang berkisah mengenai komedi romantis di antara pewaris sebuah perusahaan dengan seorang gadis dari kalangan biasa yang bernama Cha Eun Sang. Ia mempunyai seorang ibu tuna wicara yang bekerja sebagai pembantu rumah tangga dan memliki seorang kakak perempuan yang kuliah di Amerika. Akan tetapi, pada akhirnya Cha Eun Sang mengetahui bahwa di Amerika, kakaknya tidak kuliah dan hal ini membuat Cha Eun Sang marah karena uang hasil jerih payah ibunya telah dihabiskan untuk membiayai kakaknya. Hal ini mengakibatkan Cha Eun Sang dan ibunya diusir dari kontrakan karena tidak bisa melunasi sewa. Kemudian ibunya meminta izin kepada majikannya agar anaknya bisa tinggal di kamar pembantu. Majikannya memperbolehkan tinggal di rumahnya tapi dengan syarat seolah-olah dia tidak tinggal di sana.

Untuk menganalisis kelas sosial dalam drama The Heirs ini, peneliti menggunakan sastra Marxis. Teori ini berpendapat bahwa sastra dianggap sebagai produk dari kekuatan sosial dan ideologi. Berdasarkan pemaparan di atas, penelitian ini bermaksud untuk mengungkapkan bentuk pertentangan kelas sosial pada tokoh utama dalam drama The Heirs dan penyebab terjadinya pertentangan kelas sosial pada tokoh utama dalam drama The Heirs.

\section{METODE}

Penelitian ini merupakan penelitian kualitatif deskriptif karena penelitian ini berusaha memahami dan memaparkan pertentangan sosial pada tokoh utama dalam drama The Heirs. Hal ini senada dengan yang dikatakan Moleong bahwa penelitian kualitatif adalah sebuah prosedur penelitian yang menghasilkan data deskriptif berupa kata-kata tertulis dan lisan tentang sifat individu, keadaan, gejala dari kelompok tertentu yang dapat diamati (Moleong, 1994:6).

Sumber data utama dalam penelitian ini adalah drama The Heirs. Peneliti mendapatkan data ini dari portal movie online. Untuk mendapatkan data pertentangan sosial pada tokoh utama dalam drama ini, peneliti menontonnya, membaca subtitle berbahasa Indonesia yang tertera dalam setiap scene, dan kemudian mencatat hal-hal yang berkaitan dengan pertentangan kelas sosial pada tokoh utama (Kaelan, 2012:167-168).

Sedangkan untuk analisis data, peneliti menggunakan model analisis yang dikemukakan oleh Miles dan Huberman yang terdiri dari empat langkah, yaitu pengumpulan data, reduksi data, penyajian data, penarikan kesimpulan. Dalam setiap melakukan keempat langkah ini, peneliti selalu mengaitkan setiap langkah dengan tujuan penelitian (Miles dan Huberman, 1994:30).

\section{HASIL DAN PEMBAHASAN}

\section{Bentuk Pertentangan Kelas Sosial pada Tokoh Utama dalam Drama The Heirs}

Berdasarkan pada konteks tempatnya, maka pertentangan kelas sosial pada tokoh utama dalam drama The Heirs terjadi di dua tempat, yaitu di sekolah dan di rumah. Adapun penjabarannya adalah sebagai berikut.

\section{Di Sekolah}

Data 1 diperoleh pada episode ke 5 menit ke 32:46, yaitu adegan ketika ibunya mengantarkan minuman kepada ketua komisaris. 
Ketua : "Seperti yang kau ketahui, yayasanku memiliki beberapa sekolah. Kenapa kau tidak memindahkan putrimu ke SMA Jeguk?. Anggap saja itu sebagai ungkapan terima kasihku!. Anak-anak perlu memiliki impian meskipun lingkungannya keras."

Ibu Eun : (membungkukkan kepala berkali-kali sebagai ucapan terima kasih).

Sebelum terjadi percakapan di atas, sebenarnya terdapat percakapan antara tokoh komisaris dengan bawahannya yang bertugas untuk memata-matai putranya. Saat itu bawahannya menyerahkan foto-foto putranya. Komisaris mendecakkan lidahnya melihat foto putranya dengan perempuan yang tidak sederajat dengannya. Salah satu dari foto-foto itu adalah fotonya Kim Tan dengan Eun Sang ketika mereka di Amerika dan ketika Kim Tan menemui Eun Sang di sekolahnya. Sedangkan ketika peristiwa itu terjadi, Kim Tan sudah dijodohkan dengan putri konglomerat oleh ayahnya (Komisaris). Karena melihat foto-foto itu, akhirnya Komisaris memberikan beasiswa kepada Eun Sang yaitu pindah ke SMA Jeguk. SMA yang sangat mahal dan mempraktekkan tingkatan-tingkatan kelas. Pembicaraan para siswa di sekolah ini adalah seputar bisnis orang tua mereka. Di SMA terdapat empat tingkatan kelas sosial, yaitu:

a. Kelompok pewaris manajemen atau pengusaha

Kelompok ini menempati kelas sosial tertinggi di SMA Jeguk. Yang berada dikelas ini adalah putra dan putri dari keluarga konglomerat seperti Kim Tan, Choi Young Do dan Yoo Rachel. Kelas ini sering melakukan penindasan terhadap kelas kepedulian sosial.

b. Kelompok pewaris saham

Kelompok ini menempati kelas sosial kedua di SMA Jeguk. Mereka yang berada di kelompok ini tidak akan pernah terjun langsung dalam dunia bisnis, namun mereka adalah pemegang saham utamanya. Ladang bisnis orang tua kelas sosial ini adalah industri TV dan agen artis terkenal. Mereka yang berada dalam kelas sosial ini selalu membicaran tentang harga naik turunnya saham.

c. Kelompok pewaris kehormatan

Kelompok ini menempati kelas sosial ketiga. Mereka yang berada di kelompok ini adalah anak menteri, polisi, hakim, dan pemilik firma hukum. Mereka yang berada dalam kelas sosial ini seringkali berbicara mengenai beberapa kasus yang sedang ditangani oleh orang tua mereka.

d. Kelompok kepedulian sosial

Kelompok terakhir ini menempati kelas terakhir atau kelas terbawah dalam peringkat kelas sosial di SMA Jeguk. Kelompok ini merupakan kelompok dari siswa SMA Jeguk yang memeproleh beasiswa, seperti Cha Eun Sang. Siswa yang berada dalam kelas sosial ini selalu menjadi sasaran penindasan yang dilakukan oleh kelompok kelas tertinggi.

Data 2 diperoleh dari episode 7 menit ke 32:49, ketika Young Do melarang semua siswa masuk kelas karena dia ingin berbicara dengan Eun Sang.

Lee Bo Na : "Hei Choi Young Do! Memangnya ini sekolahmu? Secara teknis, ini sekolahnya Kim Tan. Jadi kenapa kau menyuruh kami keluar?"

Young Do: "Ada yang harus kutanyakan pada orang kaya baru".

Eun Sang : (melihat Young Do)

Young Do : "Jangan gugup". Lalu dia mengambil tasnya Eun Sang dan membuang semua isinya.

Eun Sang : "Apa yang kau lakukan?"

Bo Na: "Apa-apaan ini?"

Young Do : “Aku senang kau disini”. Lalu mengambil tasnya Bo $\mathrm{Na}$ dan membuang semua isinya.

Bo Na : "Hei kau gila!"

Young Do : "Bisa kau lihat? Lihatlah, kau tak pernah membelanjakan uang. Kau 
bukan orang kaya baru. Lee Bo Na! Apa benar dia orang kaya baru? Kudengar kau tahu sedikit tentangnya". (Young Do membandingkan tasnya Eun Sang dengan $\mathrm{Bo} \mathrm{Na}$ )

Boo Na : "Aku tak tau! Apa pedulimu dia orang kaya baru atau tidak?(sambil merapikan barang-barangnya)"

Young Do : "Aku peduli. Jika anak grup peduli sosial berpura-pura dia itu orang kaya baru, bukankah dia sudah menipu seantero sekolah. Tentu saja aku peduli. Kita semua korban, ya kan?”

Eun Sang: "Aku tidak akan minta maaf. Minggirlah! (dengan suara gemetar tapi dia mencoba bersikap tenang)"

Young Do : “Apa yang membuatmu begitu berani? Boleh kutanya?"

Dari percakapan di atas, dapat diketahui bahwa tokoh Young Do bersikeras ingin membuktikan bahwa Eun San bukan orang kaya baru melainkan dari grup peduli sosial. Choi Youg Do adalah sahabat Kim Tan. Mereka berdua sering melakukan penindasan terhadap siswa atau siswi yang berada di kelompok kepedulian sosial. Namun pada akhirnya, Kim Tan sudah tidak melakukan penindasan terhadap kelompok ini karena dia tidak sudah tidak bersahabat dengan Young do.

Sebelum terjadi percakapan di atas, sebenarnya terdapat kejadian ketika Eun Sang masuk ke sekolah itu. Pada suatu hari ada siswa baru yaitu Eun Sang yang berasal dari kelompok kepedulian sosial. Dia pergi ke sekolah tanpa memakai seragam karena dia tidak punya uang untuk membeli seragam. Dia melihat semua siswa dan siswi diantarkan orang tuanya pakai mobil kecuali dia yang hanya berjalan kaki sendiri. Ketika berada di dalam kelas, Eun Sang diminta memperkenalkan diri.

Ketika dia memperkenalkan diri, ada salah satu siswa yang bertanya "Apa alasanmu pindah ke SMA ini?. Eun Sang tidak bisa menjawab karena dia gugup dan takut. Pertanyaan itu dilontarkan lagi oleh salah satu siswa ketika jam istirahat. Dia bertanya"Ada dua alasan anak pindah ke SMA ini yaitu grup peduli sosial dan orang kaya baru, kau termasuk yang mana?". Lagi-lagi Eun Sang tidak berani menjawab. Tibatiba ada Kim Tan yang memanggilnya orang kaya baru agar tidak ada yang menindas Eun Sang. Sejak saat itulah anak-anak mengira bahwa Eun Sang adalah orang kaya baru. Akan tetapi Young Do tidak percaya karena dia pernah melihat Eun Sang bekerja sebagai pengantar pizza. Oleh karena itu, Young Do melakukan penindasan kepada Eun Sang agar dia mengetahui kebenaran status Eun Sang.

Data 3 diperoleh pada episode 8 menitke 52:38, ketika makan siang di kantin sekolah.

Young Do: "Duduklah!"

EunSang: (hanya memandang kursi)

Young Do: "Apa yang kau lakukan? Duduklah!” EunSang: "Aku tidak ingin makan denganmu”. Young Do: "ini hanya makan siang. Kau membuatku malu (sambil memindahkan piring Eun Sang)"

EunSang : (Hanya melihat makanannya karena dia merasa ketakutan duduk di kursi itu)

Young Do : "Kenapa kau tidak makan?"

EunSang : "Apa artinya duduk di kursi ini?"

Young Do : “ Tidak ada, aku hanya menyukai kursi ini".

EunSang : “Jika kau ingin menggunakanku untuk membuat Kim Tan marah kau harus berhenti karena aku tidak ada hubungan apa-apa dengannya.

Young Do : "Benarkah? Aku juga tidak ada hubungan dengannya".

Kim Tan : "Apa yang kaulakukan?"

Young Do : "Menurutmu apa? Kami sedang makan siang".

Kim Tan : "Berdiri! Aku bilang berdiri!"

EunSang: (berdiri dengan membawa makanannya)

Young Do : (Membanting sumpit dan berdiri) Apa kau tidak tahu sopan santun? Apakah aku harus memberitahumu di depan semua orang?" 
Kim Tan : "Kita akan makan bersama, ayo pergi (sambil menggandeng tangan Eun Sang)".

Ketika Eun Sang berjalan tiba-tiba Young Do menyangga kakinya sampai ia terjatuh dan makanannya tumpah keseragamnya. Eun Sang sesenggukan karenaketakutan.

Di kantin sekolah memiliki peraturan, yaitu ada kursi khusus untuk kelompok kepedulian sosial, yang mana tidak sembarang orang bisa duduk di kursi itu. Tokoh Eun Sang merasa ketakutan karena dia disuruh Young Do duduk di kursi itu. Dia takut akan ditindas dan dipermalukan di depan semua orang. Jika seorang siswa mengalami penindasan, maka serangkaian konsekuensi akan diterimanya seperti tidak akan ada seseorang yang berani menolong, tidak akan ada yang mau berbicara dengannya, dan dia tidak mempunyai teman selamanya sampai dia pindah ke sekolah lain. Cha Eun Sang takut hal itu akan terjadi pada dirinya.

Data 4 diperoleh pada episode 14 menit ke 13:42, ketika Rachel datang ke rumah Kim Tan.

Rachel menemukan seragam Eun Sang di jemuran rumah Kim Tan. Lalu Rachel membuangnya ke tempat sampah sekolah. Hal itu membuat Eun Sang pergi ke sekolah tidak memakai seragam. Eun Sang menemui Rachel dan menanyakan keberadaan seragamnya.

Eun Sang : "Dimana seragamku?"

Rachel : "Aku membuangnya ke tempat sampah. Sekarang pasti sudah dibakar".

EunSang : (Pergi ke tempat sampah untuk mencari seragamnya)

Rachel : (Mengikuti Eun Sang)

Eun Sang mengaik-ngaik tempat sampah dan akhirnya menemukan seragamnya.

Eun Sang : "Ibu membelikan ini untukku. (sambil menangis)".

Rachel : "Apakah itu sakit? Apakah itu menyakiti hatimu? Bayangkan bagaimana perasaanku ketika aku menemukan itu di rumah Kim Tan”.

EunSang : "Apakah kau merasa lebih baik sekarang? Kau suka melihat aku mengaik-ngaik sampah untuk mencari ini?"

Rachel : "Apa maksudmu? Apakah kau tidak tahu siapa aku? Inibaru awalnya. Anak seorang pelayan berpura-pura menjadi orang kaya baru sungguh membuatku kesal dan dia sedang berpacaran dengan tunanganku.

EunSang: "Apa yang bisa membuat lebih baik?" Rachel : "Bersihkan sampah ini. Kamu pasti sudah belajar dari ibumu".

EunSang : (menampar Rachel)

Dari percakapan di atas, dapat diketahui bahwa tokoh Eun Sang sudah berani melawan siapapun yang menindasnya. Dia tidak takut kalau akhirnya semua siswa tahu kalau dia bukan orang kaya baru melainkan dari kelompok kepedulian sosial. Rachel adalah tunangan Kim Tan akan tetapi Kim Tan tidak menyukainya. Ayah Kim Tan memaksanya untuk bertunangan dengan Rachel karena Rachel berasal dari keluarga konglomerat. Rachel memperlakukan Eun Sang seperti perlakuan dalam percakapan di atas karena dia cemburu melihat Eun Sang dengan Kim Tan. Dalam drama ini para orang tua menjodohkan anaknya dengan keluarga konglomerat dan yang sepadan dengannya agar status sosial mereka terjaga.

\section{Di Rumah}

Data 1 diperoleh pada episode ke 4 menit ke 07:45, ketika dia pulang ke rumah.

Eun Sang : "Kok kosong?”

Pemilik kontrakan : "Ah..Eun Sang!"

Eun Sang : "Ahjumma, mengapa ruangannya kosong? Ibuku pergi kemana?"

Pemilik kontrakan : "Ibu sudah pindah. Dia bilang dia bekerja menjadi pembantu rumah tangga dan tinggal disana".

Dan beberapa menit kemudian terdapat percakapan antara Eun Sang dan ibunya. 
Eun Sang : “Apa? uang itu adalah deposit kontrakan kita?"

Ibunya : "Kemana lagi aku harus mencari uang sebanyak itu? (pakai bahasa isyarat karena ibunya tunawicara)"

Eun Sang : "Kau membuatku gila. Ibu apa yang ada di pikiranmu? kenapa kau memberikan uang kepadanya? Pernikahannya semuanya bohong.

Dari percakapan di atas, terlihat bahwa betapa marahnya Eun Sang kepada kakaknya karena sudah membohongi dirinya dan ibunya. Eun Sang mempunyai seorang kakak yang tinggal di Amerika untuk melanjutkan sekolah, akan tetapi kakaknya telah membohonginya. Dia sebenarnya tidak kuliah. Tiba-tiba dia menelpon ibunya dan memberitahu kalau dia mau menikah di Amerika dan meminta uang untuk modal pernikahan. Ibunya mau mengirimkan uang untuk kakaknya akan tetapi Eun Sang melarangnya. Eun Sang marah kenapa dia menikah tapi tidak mengundang ibunya dan adiknya. Dia iri pada kakaknya yang hidup mewah di Amerika. Akhirnya Eun Sang mengantarkan uang itu ke Amerika dan menemui kakaknya. Setelah tiba di Amerika ternyata kakaknya tidak menikah. Uang yang seharusnya dipakai untuk membayar sewa rumah di ambil kakaknya. Karena hal itu Eun Sang dan ibunya diusir dari kontrakan. Kemudian ibunya meminta izin kepada majikannya agar anaknya bisa tinggal di kamar pembantu. Majikannya memperbolehkan tinggal di rumahnya tapi dengan syarat dia tinggal di sana tapi seolah-olah dia tidak tinggal di sana.

Data 2 diperoleh dari episode 16 menit ke 00:08, ketika Komisaris memberinya 2 tiket.

Komisaris : “Aku akan memberimu waktu 2 minggu. Selama 2 minggu itu kau bisa bertemu dengan Kim Tan sesuka hatimu. Tapi, setelah 2 minggu ka akan pergi ke tempat yang sudah aku tentukan. Bukan di Korea dan tempatnya akan sangat berbeda dengan Amerika, Inggris, maupun Perancis. Kau bisa memilih salah satu dari 2 tempat itu (sambil memberikan 2 tiket) Satu hal yang pasti, ini adalah satu-satunya tiket yang bisa mengantarkanmu naik ke atas, dimana Tan dikurung.

Eun Sang : (menangis tersedu-sedu sambil memandangi 2 tiket yang ada di depannya)

Komisaris marah karena melihat anaknya berpacaran dengan anak pelayan. Hal itu adalah jalan terakhir buat Eun Sang karena cara sebelumnya tidak membuat Eun Sang mengenali siapa dirinya. Cara itu adalah memberikan beasiswa pada Eun Sang untuk sekolah di SMA Jeguk. Sebenarnya Komisaris memberi beasiswa itu untuk memperlihatkan siapa Eun Sang sebenarnya bahwa dia itu tidak pantas untuk Tan Kim.

Komisaris berkata "Setidaknya dia akan mendengar dari 100 anak kenapa dia tidak pantas untuk Tan". Dan akhirnya Eun Sang pergi meninggalkan semuanya. Dia tinggal di Korea tepatnya di pinggir pantai. Setelah itu ibunya mencari pekerjaan tapi tidak ada satupun yang menerimanya karena dia tunawicara.

Hal ini sesuai dengan pendapat Marx tentang kelas borjuis bahwa mereka adalah penguasa. Kelas borjuis bisa bertindak sekehendak mereka karena mereka tidak bergantung pada kelas proletar. Sedangkan kelas proletar hanya bertindak sebagai obyek kelas borjuis, yaitu menerima dan patuh karena kelas ini membutuhkan kelas borjuis untuk bertahan hidup.

\section{Penyebab Terjadinya Pertentangan Kelas Sosial pada Tokoh Utama dalam Drama The Heirs}

Pertentangan kelas sosial pada tokoh utama dalam drama The Heirs yang terjadi di sekolah dan di rumah disebabkan oleh adanya hubungan asmara antara kelas borjuis dengan kelas proletar dan implementasi sistem hirarki di SMA Jeguk. 
Adapun penjabarannya adalah sebagai berikut:

\section{Di sekolah}

Data diperoleh pada episode 6 menit ke 04:18.

Chan Young: "Aku akan memberitahumu masalah penting yang ada di depanmu.

Eun Sang : "Kenapa kedengarannya begitu serius? Kau menakutkanku".

Chan Young: "Dengarkan baik-baik. Ada hirarki yang sangat ketat di sekolah ini".

Eun Sang : "Hirarki?"

Chan Young : (menjelaskan tentang tingkatantingkatan kelas) dan kelas keempat adalah kau dan aku

Eun Sang : "Grup peduli sosial?

Chan Young : “ Merujuk pada anak-anak yang masuk melalui jalur kepedulian sosial".

Percakapan di atas menunjukkan bahwa sistem sekolah mempraktekkan sistem hirarki, yaitu system pembagian kasta atau tingkatan berdasarkan pada kelas sosial yang melekat pada para siswa. Pembagian kelas sosial ini jelas menimbulkan kesenjangan di antara kelas-kelas sosial yang ada di sekolah dan sangat rawan menimbulkan konflik. Pembagian kelas ini bila dipandang dari kacamata Marxis, maka akan nampak adanya kelompok borjuis dan kelompok proletar.

Data 2 diperoleh pada episode 6 menit ke 17:53.

Eun Sang : “Alasan Young Do berbicara padaku dan alasan gadis-gadis lain melotot kepadaku itu adalah karena kau. Sekarangpun mereka mengintip selagi kita bicara. Bukan Young Do yang harus aku jauhi tapi kau Kim Tan".

Percakapan di atas menunjukkan bahwa yang menyebabkan Eun Sang dibuli adalah karena kedekatannya dengan Kim Tan. Dua anak yang selalu membuli Eun Sang adalah Young
Do dan Rachel. Alasan Young Do membuli Eun San adalah karena ia ingin menjadikan Eun Sang sebagai umpan untuk memancing emosi Kim Tan. Sedangkan alasan Rachel adalah karena Eun Sang berpacaran dengan Kim Tan.

\section{Di Rumah}

Data 1 diperoleh pada episode 8 menit ke 29:19.

Komisaris : "Kau yang memperkenalkan Park Hee Nam (ibunya Eun Sang) kepada kami. Bagaimana kamu mengenalnya?"

Sekertaris : "Dia adalah tetanggaku dan dia menjalankan kios berjalan bersama semuanya. Dia benar-benar baik jadi aku sering ke sana untuk minum”.

Komisaris : "Ibunya Tan mengatakan padaku kalau dia mempunyai banyak hutang".

Sekretaris : "Sebelum ayahnya Eun Sang mrninggal dia dirawat di rumah sakit untuk waktu yang lama, tagihan rumah sakit itulah hutangnya. Dia masih terus melunasinya.

Komisari : "Oh..begitu. kau tahu bahwa aku mengirim Eun Sang ke SMA Jeguk?”.

Sekertaris : "Aku sudah mendengarnya dari anakku Chan Young. Aku sudah lama ingin bertanya kepada anda, mengapa anda mengirim Eun Sang ke SMA itu?

Komisaris : "Dia akan mendengar setidaknya dari 100 anak kenapa dia tidak pantas untuk Tan".

Dari percakapan di atas, dapat diketahui penyebab terjadinya pertentangan kelas di rumah, yaitu karena komisaris tidak rela kalau anaknya (Kim Tan) menjalin hubungan dengan putri pelayan (Eun sang). Komisaris mengetahui hal tersebut dari bawahannya yang ditugaskan untuk memata-matai anaknya.

\section{SIMPULAN}

Bentuk pertentangan kelas sosial dalam drama The Heirs adalah penindasan yang dilakukan oleh kelas borjuis kepada kelas proletar. Peristiwa penindasan ini terjadi di sekolah dan di 
rumah tempat Eun Sang tinggal. Penindasan itu berupa penindasan fisik dan psikis. Sedangkan penyebab munculnya pertentangan kelas sosial karena sekolah itu menerapkan sistem hirarki, dan adanya hubungan asmara antara kelas borju dan kelas proletar.

\section{DAFTAR PUSTAKA}

Jefferson, A. and R. (1989). Modern Literary Theory. London: B.T. Batsford Ltd.

Kaelan. (2012). Metode Penelitian Kualitatif Interdisiplinner Bidang Sosial, Budaya, Filsafat, Seni, Agama dan Humanoira. Yogyakarta: Paradigma.
Matthew B. Miles, and A. M. Huberman. (1994). Qualitative Data Analysis (second edition). London: Sage Publications Inc.

Nurgiyanto, B. (2007). Teori Pengkajian Fiksi. Yogyakarta: Gajah Mada University Press. Setiadi, Elly M, dan Kolip, Usman. (2011). Pengantar Sosiologi: Pemahaman Fakta dan Gejala Permasalahan Sosial. Jakarta: Kencana.

Soekanto, S. (1987). Soiologi Suatu Pengantar. Jakarta: Rajawali Press.

Sunarto, K. (1993). Pengantar Sosiologi. Jakarta: Lembaga Penerbit Fakultas Ekonomi Universitas Indonesia. 